\title{
Editorial to the First Issue of Childhood Vulnerability Journal
}

\author{
Sabine Andresen ${ }^{1} \cdot J_{\text {Jlia Koenig }}{ }^{2} \cdot$ Gill Main $^{3}$
}

Published online: 23 August 2019

(C) Springer Nature Switzerland AG 2019

Recent decades have seen a proliferation of interest in children and childhood studies from academics, policy makers, and practitioners working with children and families. This interest reflects several shifts in perspectives on children and childhood which have revolutionised thinking about children - from 'objects' to 'subjects' to 'agents', and from 'becomings' to 'beings'.

These shifts have been informed by a range of academic and policy developments. The development of the new social studies of childhood has posed an important challenge to developmental approaches to understanding children and childhood. While traditional, developmental approaches position children as interesting because they are growing towards adulthood, newer sociological approaches position children and childhood as a source of interest in their own right, during childhood and not only because children will later become adults. Biological immaturity is a fact - but the precise nature of 'childhood' is socially constructed, and varies according to time, place, and culture. These academic developments have informed and coincided with policy changes. The need to respect children and childhood as of relevance in its own right has been promoted by the phenomenally successful United Nations Convention on the Rights of the Child, which sets out for children a range of rights supplemental to the human rights accorded to all irrespective of age, reflecting their unique social and developmental position. Importantly, these rights are not just about protecting children from harm and providing for their development - they also relate to children's

Sabine Andresen

S.Andresen@em.uni-frankfurt.de; https://www.uni-frankfurt.de/55824124/Andresen

Julia Koenig

https://www.allgemeine-erziehungswissenschaft.uni-mainz.de/2609-2/

Gill Main

https://essl.leeds.ac.uk/education/staff/151/dr-gill-main

1 Department of Educational Sciences, Institute for Social Pedagogy and Adult Education, Goethe University Frankfurt, Frankfurt, Germany

2 Department of Social Sciences, Institute for Education, Gutenberg University Mainz, Frankfurt, Germany

3 School of Education, University of Leeds, Leeds, England 
participation. That is, a fundamental principle of the UNCRC is that children's perspectives and preferences must not be ignored in decisions affecting their lives.

This emphasis on participation and agency reflect sociological as well as developmental approaches to childhood, and has begun to redress a long-standing imbalance which has emphasised children's futures over their presents. Several successful and important academic journals have been developed which problematise developmental thinking, emphasising children's agency and ability rather than their dependency and deficit. But much work remains to be done, especially in relation to achieving a balance between what are often treated as dichotomous perspectives positioning children either as 'agents' or as 'vulnerable'.

Our key aim in establishing the Childhood Vulnerability Journal is to acknowledge that an important middle ground exists, in which children can be positioned as both agentic and vulnerable. This positioning is similar, in many ways, to adults - coinciding vulnerability and agency are characteristic of the human condition. But children as a social group present additional and different vulnerabilities and opportunities for agency, associated with both developmental conditions and social norms around childhood.

A further aim is to provide a space for genuinely inter- and transdisciplinary thinking on children and childhood. Developments in perspectives have occurred across a range of disciplines with relatively little cross-communication, and as a result there is a risk of important perspectives being 'rediscovered' in multiple disciplines. As part of the process of establishing this journal we were fortunate enough to have the opportunity to organise an interdisciplinary conference. This brought together researchers from diverse fields - among them education, psychology, social policy, media, literature and history - to share the ways in which we use concepts of agency and vulnerability in our research.

In this issue we focused on three dimensions that are considered important for further research:

a) We seek to understand vulnerability in childhood as part of the basic structure of human life, and thereby to question the narrow definitions often applied within the field. Here, a central question concerns the role of the phenomenon of human and, more specifically, childhood dependence within the "generational order". The fact that children depend on certain framing conditions during the course of growing up, that they are in need of human activities involving care and welfare, but also love and teaching, is clear confirmation of their dependence as human beings - but not necessarily as children. Here the focus will be on questions of how dependencies between the generations are negotiated within the generational order and how this produces not only childhood but also youth and adulthood.

b) We aim to overcome the dualistic scheme of vulnerability as opposed to agency, while finding ways to address the multiple interdependencies characterizing the lives of children as being both vulnerable and social as well as moral actors themselves. In doing so, the dependent status of the child will be re-evaluated from multiple (inter)disciplinary perspectives. By bringing into conversation rather different disciplinary perspectives featuring at times opposing paradigms of vulnerability in childhood, we aim to generate a transdisciplinary synergy. Thereby, we aspire to revisit the concepts of well-being and resilience in a consistent way without having to allocate them on one or the other side of a theoretical framework positioning vulnerability and agency as being mutually exclusive. 
c) We strive for an intersectional approach to understanding the vulnerabilities children experience and are subjected to in different social-economic as well as social-ecological spaces and situations, which includes children's own perspectives.

The purpose of the Childhood Vulnerability Journal can be summarised as:

- To encourage critical and both inter- and transdisciplinary engagement with the concept of vulnerability as it can be applied to children and childhood

- To prioritise children's perspectives and child-centric research as vital to understanding how the concepts of 'childhood' and 'vulnerability' interrelate

- To challenge the dichotomous framing of 'vulnerability' and 'agency' within dominant approaches to the study of children and childhood

This first issue draws on some of the various disciplines and topics which we intend to address within the Childhood Vulnerability Journal.

Yochay Nadan and Jill Korbin focus on a context-sensitive approach. The paper explores how intersectionality frameworks provide a better understanding of the concept of vulnerability. Nadan and Korbin offer meaningful ideas about how to research the difference in children's living conditions in a global world.

Nazan Maksudyan's article comes from a historical perspective as she reconstructs the history of the Armenian genocide from children's points of view. She responds to the concept of vulnerability by focusing on the survival strategies of Armenian children during the genocide and its aftermath. Her critical approach to victimizing children includes systematic consideration of the links between vulnerability and agency. "In their struggle to survive, Armenian children took initiative, made personal decisions, manipulated circumstances, and thus became active agents", she writes.

In many studies children's voices are not heard and their perspectives have been absent. Drawing on an empirical mixed-method study on intra-family sharing - "Fair Shares and Families", Gill Main develops a child-centric model for intra-family allocation. She raises questions about inequalities between generation and gender, and highlights the "problematic nature of using the household as a unit of measurement when children are the unit of interest and/or analysis". Main formulates ideas on the relationship between vulnerability and children's material well-being.

Sabine Andresen points out that in recent years there have been some social changes in dealing with child sexual abuse in many countries. Her article is based on analyses of written reports of victims and survivors to the Independent Inquiry into Child Sexual Abuse in Germany. She uses the memories of adults to systematically explore the concept of vulnerability.

In her article on advocatory ethics and sexual politics Julia König discusses potentials and pitfalls of both conceptual and practical efforts to ensure of the best interest of the child. She argues that the necessity to determine the child's best interest negatively - from the perspective of its endangerment - makes the concept prone to (political) instrumentalizations in public discourse. At the same time, König recognizes an emancipatory potential in exactly the systematically necessary abstraction at play in socio-political instrumentalizations of the best interest of a child - it obliges to focus on each individual case: "Discussions of the best interest of the child are therefore indispensably dependent on their mediation with analyses of concrete, socially and historically always contingent constellations." 
Bringing together researchers who would not normally cross paths in discipline-specific arenas revealed that there is a wealth of cross-fertilisation waiting to be tapped. It is our aim, in establishing this journal, to create a space within which diverse academics can share their perspectives and research on children and childhood, learning from previously unconsidered fields and developing a truly transdisciplinary approach which, ultimately, will help in our shared goal of improving children's lives.

Acknowledgements We would like to thank Dr. des. Aysel Sultan for her outstanding support!

Publisher's Note Springer Nature remains neutral with regard to jurisdictional claims in published maps and institutional affiliations. 